Article

\title{
Role of Polycomb Group Protein Cbx2/M33 in Meiosis Onset and Maintenance of Chromosome Stability in the Mammalian Germline
}

\section{Claudia Baumann ${ }^{1,2}$ and Rabindranath De La Fuente ${ }^{1,2, *}$}

1 Female Germ Cell Biology Group, Department of Clinical Studies, Center for Animal Transgenesis and Germ Cell Research, School of Veterinary Medicine, University of Pennsylvania, New Bolton Center, 382 West Street Road, Kennett Square, PA 19348, USA; E-Mail: cbaumann@uga.edu

2 Department of Physiology and Pharmacology, College of Veterinary Medicine, University of Georgia, 501 D.W. Brooks Drive, Athens, GA 30602, USA

* Author to whom correspondence should be addressed; E-Mail: rfuente @ uga.edu; Tel.: +1-706-542-5864; Fax: +1-706-542-3015.

Received: 30 November 2010; in revised form: 16 December 2010 / Accepted: 6 January 2011 / Published: 11 January 2011

\begin{abstract}
Polycomb group proteins $(\mathrm{PcG})$ are major epigenetic regulators, essential for establishing heritable expression patterns of developmental control genes. The mouse PcG family member M33/Cbx2 (Chromobox homolog protein 2) is a component of the Polycomb-Repressive Complex 1 (PRC1). Targeted deletion of Cbx2/M33 in mice results in homeotic transformations of the axial skeleton, growth retardation and male-to-female sex reversal. In this study, we tested whether $C b \times 2$ is involved in the control of chromatin remodeling processes during meiosis. Our analysis revealed sex reversal in $28.6 \%$ of $\mathrm{XY}^{-/}$embryos, in which a hypoplastic testis and a contralateral ovary were observed in close proximity to the kidney, while the remaining male mutant fetuses exhibited bilateral testicular hypoplasia. Notably, germ cells recovered from $C b x 2^{\left(\mathrm{XY}^{-1-}\right)}$ testes on day 18.5 of fetal development exhibited premature meiosis onset with synaptonemal complex formation suggesting a role for $\mathrm{Cbx} 2$ in the control of meiotic entry in male germ cells. Mutant females exhibited small ovaries with significant germ cell loss and a high proportion of oocytes with abnormal synapsis and non-homologous interactions at the pachytene stage as well as formation of univalents at diplotene. These defects were associated with failure to resolve DNA double strand breaks marked by persistent $\gamma \mathrm{H} 2 \mathrm{AX}$ and $\operatorname{Rad} 51$ foci at the late pachytene stage. Importantly, two factors required for meiotic
\end{abstract}


silencing of asynapsed chromatin, ubiquitinated histone $\mathrm{H} 2 \mathrm{~A}(\mathrm{ubH} 2 \mathrm{~A})$ and the chromatin remodeling protein BRCA1, co-localized with fully synapsed chromosome axes in the majority of $C b x 2^{(--)}$oocytes. These results provide novel evidence that $\mathrm{Cbx} 2$ plays a critical and previously unrecognized role in germ cell viability, meiosis onset and homologous chromosome synapsis in the mammalian germline.

Keywords: oogenesis; pericentric heterochromatin; epigenetic modifications; chromatin remodeling; retinoic acid; sex determination

\section{Introduction}

In all sexually reproducing organisms, germ cells have the monumental task of transmitting genetic information through subsequent generations. Primordial germ cells (PGCs) must undergo epigenetic reprogramming, meiotic recombination and two subsequent chromosomal divisions in order to give rise to mature haploid sperm or eggs. Following colonization of the genital ridge (day 12.5 post coitum in mice), PGCs undergo two or three mitotic divisions before proceeding into a final round of DNA replication and entering a pre-meiotic stage [1,2]. In fetal female germ cells, the transition from mitosis to meiosis ensues approximately on day 14.5 post coitum (pc) and is characterized by a retinoic acid-dependent up regulation of meiosis-specific genes, including the synaptonemal complex protein 3 (SYCP3), followed by striking changes in chromosome configuration. In direct contrast, meiosis is not initiated in the male germline until shortly before puberty. This meiotic arrest in the male is mediated by secretion of the retinoid metabolizing enzyme CYP26B1 from Sertoli cells which promotes degradation of retinoic acid (RA) produced by the mesonephros $[1,3,4]$.

Although it is well established that RA of somatic origin is the predominant metabolic influence in triggering meiosis onset, germ cell-intrinsic factors such as the RNA-binding protein DAZL are also critical for the transition from mitosis to meiosis by promoting transcriptional activation of Stra 8 (stimulated by retinoic acid 8) [5]. Importantly, the unique chromatin conformation in mammalian germ cells and/or germline-specific histone posttranslational modifications may also underlie the specific actions of RA in both male and female germ cells [6,7]

Extensive changes in chromatin modifications are critical from the earliest stages of primordial germ cell differentiation. Global genome reprogramming events may also be dependent on signaling molecules from the surrounding somatic cells of the embryonic gonad [8-11]. Chromatin remodeling in the germline is essential to modulate chromosome structure and, hence, for the establishment of proper homologous chromosome synapsis [12-14]. Notably, biochemical analyses as well as several genetic mouse models support the existence of critical factors that might be exclusively involved in the control of germline-specific epigenetic modifications essential for the successful completion of meiotic prophase $I$ in the female as well as the male germline $[15,16]$. However, the role of epigenetic modifications in meiosis onset is less clear.

The Polycomb group $(\mathrm{PcG})$ proteins are a family of transcriptional repressors that form large multi-protein complexes, which exert their function through the modulation of higher order chromatin structure [17]. The mouse Polycomb protein M33 and its human homolog CBX2 are members of the 
Polycomb repressive complex 1 (PRC1). Mutations in the Cbx2/M33 gene induce a range of congenital birth defects such as transformations of the axial skeleton associated with premature homeotic (Hox) gene expression [18,19], in addition to severe abnormalities in sexual development including male to female sex reversal in humans [20] and mice [18,21]. Despite the impact of $C B X 2$ mutations on human health, little is known regarding the molecular and/or epigenetic factors that predispose the mammalian gonad to abnormalities of sexual differentiation. Moreover, the potential role of $C b x 2 / M 33$ in the modulation of large-scale chromatin structure during meiosis remains largely unexplored. In this study, we show that functional ablation of $\mathrm{Cbx} 2$ protein results in precocious meiotic onset in fetal male germ cells as well as a spectrum of meiotic defects in female germ cells. Our results support an essential role for Cbx 2 in germ cell development as well as the establishment of homologous chromosome synapsis during meiosis. Importantly, the meiotic phenotype observed in mutant fetal testicular germ cells indicates that $\mathrm{Cbx} 2$ plays a critical role in antagonizing the effects of retinoic acid on meiotic onset and is required for maintenance of the pre-meiotic arrest of fetal male germ cells in mammals.

\section{Results and Discussion}

\subsection{Loss of Cbx2 Function Causes Gonadal Growth Retardation and Male-to-Female Sex Reversal on a BALB/C Genetic Background}

Male-to-female sex reversal has been previously reported in a $C b x 2$ mutant mouse model established on the C57BL/6Njcl (B6) genetic background [21]. These mice carry an insertion of a neomycin cassette in exon 5 of the $C b x 2$ coding sequence resulting in deletion of the $C$-terminal portion of the $\mathrm{Cbx} 2$ protein. Although expected Mendelian inheritance patterns were observed at birth, postnatal lethality affected up to $60 \%$ of the mutant offspring before 5-6 weeks of age. In this strain, all surviving chromosomally male $C b x 2^{\left(\mathrm{XY}^{-1-}\right)}$ mice exhibited male to female sex reversal with female or intersex-type external genitalia. In addition, the internal reproductive organs consisted of bilateral ovaries containing follicles in $50 \%$ of males as well as the presence of both an ovary and a contralateral testis in $25 \%$ of mutant males [21].

Abnormalities of sex differentiation have also been reported in an alternative $C b x 2$ knockout mouse model generated on a BALB/C genetic background [18,21]. However, the extent of phenotypic sex reversal observed in this model is not known. Previous studies have documented striking differences in the level of sensitivity to phenotypic sex reversal amongst different mouse strains and genetic backgrounds [22]. Therefore, we set out to determine the type and severity of gonadal defects observed in BALB/C $C b x 2^{(--)}$knockout mice. This model [18] involved the targeted deletion of the $5^{\prime}$ untranslated region including the translation start site and the first four exons of the $C b x 2$ coding sequence leading to a null mutation of the $\mathrm{Cbx} 2$ protein. The majority of $C b x 2^{(--)}$mice in this model show neonatal lethality within hours after birth likely due to proliferative defects in several cell types and homeotic transformations [23].

Mice heterozygous for $\mathrm{Cb} x 2\left(\mathrm{Cbx} 2^{(+/)}\right)$are viable and fertile and fetuses recovered on day 18.5 post coitum from heterozygous matings revealed a normal ratio of $C b x 2^{(+/+)} / C b x 2^{(+/-)} / C b x 2^{(-/-)}$ genotypes of 31:69:33 (Figure 1A). The chromosomal sex of all 18.5 day post coitum (dpc) fetuses 
was determined by the presence or absence of Sry gene sequences as detected by PCR. Chromosomally female fetuses from all genotypes $(n=66)$ contained bilateral ovaries (Figure 1 A-C). However, $C b x 2^{\left(\mathrm{XX}^{--}\right)}$females exhibited small ovaries (Figure 1C) compared to control $C b x 2^{(\mathrm{XX}+/+)}$ females (Figure 1B). Importantly, in contrast to wild type controls (Figure 1D; $n=14$ ) chromosomally male $C b x 2^{\left(\mathrm{XY}^{-1-}\right)}$ mutant fetuses $(n=14)$ exhibited severe testicular growth retardation accompanied by impaired formation of testicular cords and in extreme cases unilateral sex reversal as reflected by the presence of a hypoplastic testis and a contralateral ovary in $28.6 \%$ of $C b x 2^{(\mathrm{XY}-1-)}$ fetuses (Figure 1E). As expected, the reproductive tracts obtained from wild type controls (Figure 1D) always exhibited bilateral testes at a caudal position towards the inguinal region. However, although the size and morphological appearance of the epididymis was similar to wild type controls, both the testis and adjacent epididymis remained in close proximity to the kidneys in $C b x 2^{\left(\mathrm{XY}^{-1-}\right)}$ mutant fetuses (Figure 1E). Histological examination on day $18.5 \mathrm{pc}$ confirmed a reduction in the size and number of testicular cords in $\mathrm{Cbx} 2^{\left(\mathrm{XY}^{--}\right)}$mutant males presenting bilateral testes as well as in the testis of mutant males showing unilateral sex reversal compared to wild type controls $C b x 2^{(\mathrm{XY}++)}$ (Figure 1F). Growth retardation and germ cell loss was apparent in both, testes (Figure 1F) as well as ovaries (Figure 1G) from $C b x 2^{(\mathrm{XY}-1-)}$ mutants compared to wild type gonads. Similarly, histological sections obtained from $C b x 2^{\left(\mathrm{XX}^{-l-}\right)}$ females confirmed the presence of small ovaries compared to controls (Figure $1 \mathrm{G}$ ).

These results indicate that, in addition to its role in sex determination, $C b x 2$ plays an important role in germ cell viability during fetal development. Importantly, our study reveals major differences in the sex reversal phenotype of $C b x 2$ knockout mice generated on the BALB/C genetic background [18] compared to the phenotype described in Cbx2 deficient mice on the C57BL/6Njcl (B6) background [21]. For example, the majority of $C b x 2$ null mice on the B6 background exhibit male to female sex reversal and approximately $50 \%$ of surviving adult mice exhibited bilateral ovaries. However, none of the knockout males analyzed contained bilateral testes [21]. In contrast, our study reveals that in the BALB/C model $<30 \%$ of mice exhibit sex reversal. This is consistent with previous studies indicating an extreme sensitivity of the B6 background to genetic perturbations of the sex determination pathway due to higher levels of expression for several genes associated with female gonadal differentiation [22,24]. Interestingly, the majority of affected males in the BALB/C model exhibit bilateral testis and mutant females presented fully differentiated ovaries, making this strain uniquely suited for the analysis of the functional ablation of $\mathrm{Cbx} 2$ in mammalian germ cells during the critical window of epigenetic reprogramming and the mitotic to meiotic transition in the germline. These results provide the first evidence indicating a role for $\mathrm{Cbx} 2$ in germ cell development.

\subsection{Premature Meiosis Onset in Fetal Cbx $2^{(X Y-1-)}$ Testicular Germ Cells}

Next, we determined whether lack of Cbx2 function in the mammalian germline is associated with abnormal chromatin-related events during meiosis. Analysis of meiotic configurations on surface spread oocytes obtained on day $18.5 \mathrm{pc}$ from the ovaries of $C b x 2^{(\mathrm{XY}-1-)}$ males exhibiting unilateral sex reversal revealed abnormal homologous chromosome synapsis involving one or two bivalents as well as several chromosome fragments as determined by synaptonemal complex staining with an anti-SYCP3 antibody (Figure 2A; red). Notably, phosphorylated histone H2AX ( $\gamma$-H2AX) remained associated with the asynapsed $\mathrm{X}$ chromosome and, to a lesser extent, with the $\mathrm{Y}$ chromosome (Figure 
2A; green). Immuno-FISH experiments using sex chromosome-specific paint probes revealed that in $>80 \%$ of $\mathrm{Cbx}^{(\mathrm{XY}-1-)}$ oocytes the $\mathrm{X}$ (green, arrow) and $\mathrm{Y}$ (red, arrowhead) chromosomes fail to undergo partial synapsis (Figure 2B). Moreover, although $\gamma \mathrm{H} 2 \mathrm{AX}$ was found associated with the sex chromosomes in the remaining mutant oocytes that exhibited sex chromosome pairing, a typical XY body was not detectable (Figure 2C, D). These results indicate that XY oocytes from sex reversed Cbx2 null gonads exhibit meiotic abnormalities in the form of chromosome breaks in addition to the lack of synapsis of the sex chromosomes.

Figure 1. Targeted deletion of $C b x 2$ leads to sex reversal and gonadal hypoplasia. (A) Correlation between genotype, phenotype and chromosomal sex in fetal offspring of heterozygous $\left(\mathrm{Cb} \times 2^{(+/)}\right)$intercrosses; (B) Gonadal differentiation in a female wild type fetus on day $18.5 \mathrm{pc}$; (C) Stage-matched $\mathrm{Cbx} 2^{(\mathrm{XX}-/-)}$ mutant fetus showing ovarian hypoplasia; (D) Anatomic disposition and testicular morphology in a male $C b x 2^{(\mathrm{XY}+/+)}$ control fetus with prominent testis cord development; $(\mathbf{E})$ Sex reversal in a $C b x 2^{(\mathrm{XY}-1-)}$ male containing both a small ovary as well as a contralateral small testis; (F) Wild type fetuses exhibit well-developed testicular cords. In contrast, mutant $C b x 2^{(\mathrm{XY}-1-)}$ fetuses with bilateral testicular hypoplasia as well as intersex embryos show poor definition of tubular structures; (G) Ovarian histology in control ovaries reveals numerous oocytes in meiosis (arrows). In contrast, mutant gonads show reduced meiotic germ cell numbers and hypoplasia.
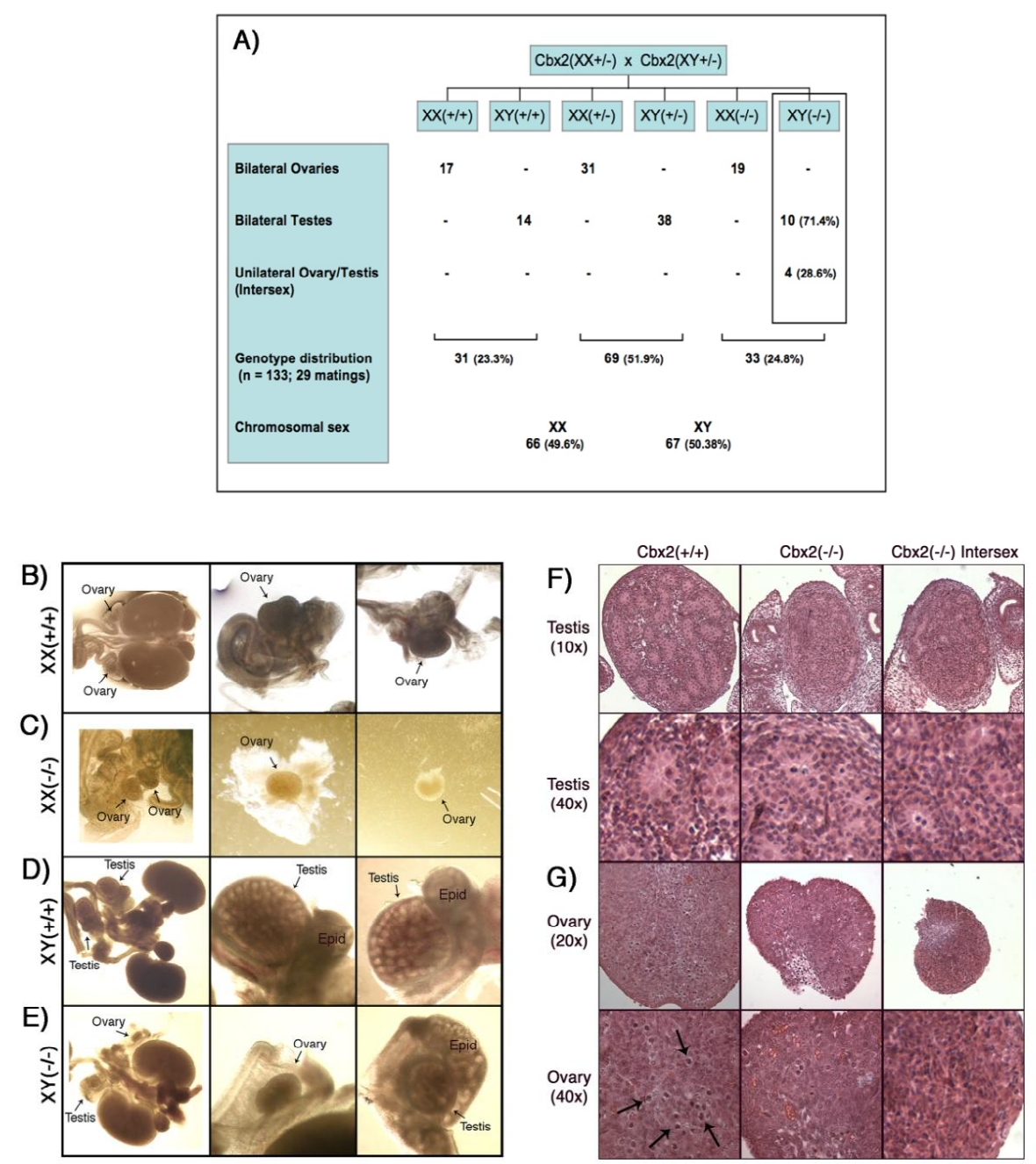
Surprisingly, our studies also revealed that germ cells obtained from the contralateral testis of $C b x 2^{(\mathrm{XY}-1-)}$ male fetuses on day $18.5 \mathrm{pc}$ undergo precocious entry into meiosis demonstrated by bona fide synaptonemal complex formation and a chromosome configuration consistent with the zygotene stage of meiosis with asynapsed chromosomes and diffuse $\gamma \mathrm{H} 2 \mathrm{AX}$ staining (not shown). Strikingly, premature meiotic germ cells were also present in $C b x 2^{(\mathrm{XY}-1-)}$ mutant males with bilateral testes, albeit at less advanced stages of prophase I compared to XY ovarian oocytes (Figure 2E, F). These results indicate that $\mathrm{Cbx} 2$ plays a critical role in the pathway responsible for the pre-meiotic arrest in the mammalian male germline. Abnormal chromosome synapsis in $C b x 2^{(\mathrm{XY}-1-)}$ mutants suggests, moreover, a role for $\mathrm{Cbx} 2$ in meiotic chromosome synapsis in the male germline. However, whether chromosome synapsis and $\mathrm{XY}$ body formation are affected in $\mathrm{Cbx} 2^{\left(\mathrm{XY}-{ }^{--}\right)}$spermatocytes undergoing precocious meiosis remains to be investigated.

Figure 2. Precocious meiosis onset in $C b x 2^{(\mathrm{XY}-1-)}$ fetal gonads. (A) $C b x 2^{(\mathrm{XY}-1-)}$ oocyte recovered from an ovary of a unilaterally sex reversed embryo showing completely asynapsed sex chromosomes and persistent $\gamma \mathrm{H} 2 \mathrm{AX}$ staining associated with the X chromosome; (B) The position of the X (green, arrow) and the Y (red, arrowhead) chromosome is shown; (C, D) Partial synapsis of the sex chromosomes associated with abundant $\gamma \mathrm{H} 2 \mathrm{AX}$ signals (green) at sex chromatin and autosomes in a $C b x 2^{(\mathrm{XY}-1-)}$ oocyte at the late zygotene-early pachytene stage; $(\mathbf{E}, \mathbf{F})$ Evidence for precocious onset of meiotic prophase I in fetal testicular germ cells obtained from a $C b x 2^{\left(\mathrm{XY}^{-1-}\right)}$ embryo with bilateral testes. Synaptonemal complexes at meiotic chromosome cores are labeled with SYCP3 (red) and $\gamma \mathrm{H} 2 \mathrm{AX}$ staining (green). DNA is shown in blue. Scale bar $=10 \mu \mathrm{m}$.

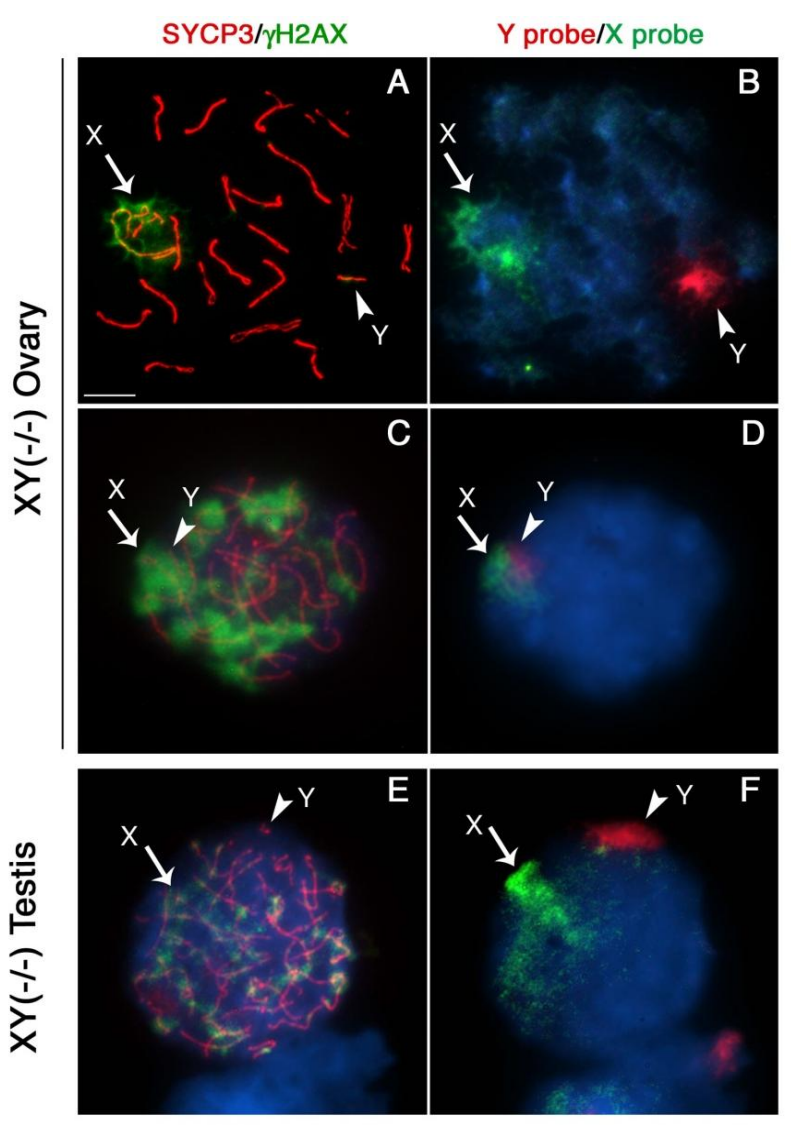


Our results are consistent with previous studies on the meiotic prophase configuration in XY oocytes obtained from the $X Y^{\text {tdym1 }}$ mouse strain, in which only $19 \%$ of oocytes exhibit partial synapsis of the sex chromosomes with no apparent sex body formation. Interestingly, in this model, histone posttranslational modifications such as ubiquitinated $\mathrm{H} 2 \mathrm{~A}$ remained associated with the $\mathrm{X}$ chromosome in $50 \%$ of oocytes [25]. However, the functional significance of these histone modifications for transcriptional silencing of the sex chromosomes in XY oocytes requires further investigation.

Notably, the identification of fetal male germ cells with precocious synaptonemal complex formation and a zygotene-like configuration on day $18.5 \mathrm{pc}$ constitutes the first evidence indicating that $\mathrm{Cbx} 2$ may play a critical role in maintenance of the pre-meiotic arrest in fetal male germ cells. Previous studies elegantly demonstrated that treatment of embryonic testes with retinoic acid agonists or inhibitors of the RA metabolizing enzyme CYP26 induce premature Stra8 expression in cultured male gonads $[3,4]$. In addition, treatment of fetal testis with the histone deacetylase inhibitor TSA induced Stra8 expression and SYCP3-positive staining on histological sections [7]. However, the presence of meiotic figures in these experimental systems remained to be demonstrated. Our results show for the first time that in the absence of $\mathrm{Cbx} 2$ function, fetal testicular germ cells prematurely transit into meiosis and exhibit synaptonemal complex formation, albeit at a lower frequency compared to ovarian germ cells. Results obtained following exposure of fetal testes to histone deacetylase inhibitors suggest that, in addition to the stimulus provided by RA, epigenetic mechanisms might also contribute to prevent premature meiosis onset in the male germline [7]. Interestingly, valproic acid, a specific inhibitor of histone deacetylases, has been recently shown to reduce the expression of $C b x 2$ transcripts in mouse embryos on day 8 pc [26]. This suggests that the role of Cbx 2 in modulating large-scale chromatin structure may be critical for antagonizing the potential effects of retinoic acid exposure on premature meiotic entry in the male germline. In support of this notion, previous studies indicate that $\mathrm{Cbx} 2$ is essential to control the developmental window of responsiveness to retinoic acid during fetal development [19].

\subsection{Loss of Cbx2 Results in Abnormal Chromosome Synapsis and Structural Damage of Meiotic} Chromosomes in Female Germ Cells

Cbx2 associates with pericentric heterochromatin domains during mitosis in both murine somatic and embryonic stem cells. The protein also localizes to facultative heterochromatin at the inactive $\mathrm{X}$ chromosome suggesting a potential role in heterochromatin formation [27-29]. However, whether Polycomb group proteins, such as $\mathrm{Cbx} 2$, play a role in meiotic chromosome synapsis in the female germline is not known. Therefore, we undertook a detailed analysis of meiotic synapsis and recombination events in Cbx 2 mutant oocytes. The dynamics of chromosome synapsis was determined following simultaneous staining of the lateral elements with SYCP3 (red) as well as the central elements of the synaptonemal complex with SYCP1 (green). At the pachytene stage, $80 \%$ of wild type oocytes $(n=90)$ exhibited fully synapsed chromosome bivalents (Figure 3A arrow, C). In contrast, mutant oocytes $(n=71)$ exhibited a significant increase in the incidence $(57 \%)$ of abnormal synapsis (Figure 3B, arrowhead) and Figure 3C. Moreover, chromosomal associations between two partially synapsed bivalents, indicative of non-homologous chromosome interactions (arrows), were commonly observed in $>30 \%$ of $\mathrm{Cbx} 2^{\left(\mathrm{XX}^{--}\right)}$oocytes (Figure 3B, C). These results indicate a previously 
unrecognized role of $\mathrm{Cbx} 2$ in chromosome pairing and homologous chromosome synapsis in female germ cells.

Figure 3. Abnormal synapsis and non-homologous chromosome interactions in $C b x 2^{(\mathrm{XX}-/-)}$ mutant oocytes. (A) Chromosome synapsis (arrow) in control oocytes at the pachytene stage showing complete co-localization of lateral (SYCP3, red) and central (SYCP1, green) elements of the synaptonemal complex; (B) Stage-matched $C b x 2^{\left(\mathrm{XX}^{-1-}\right)}$ oocyte presenting abnormal synapsis (arrowhead), non-homologous chromosome interactions between two partially synapsed bivalents (arrows) as well as structural damage in the form of prominent chromosome breaks (asterisk). DNA is shown in blue; (C) Proportions of pachytene stage oocytes obtained from control and mutant fetuses on day $18.5 \mathrm{pc}$ showing incomplete chromosome synapsis and non-homologous interactions. Scale bar $=10 \mu \mathrm{m}$.
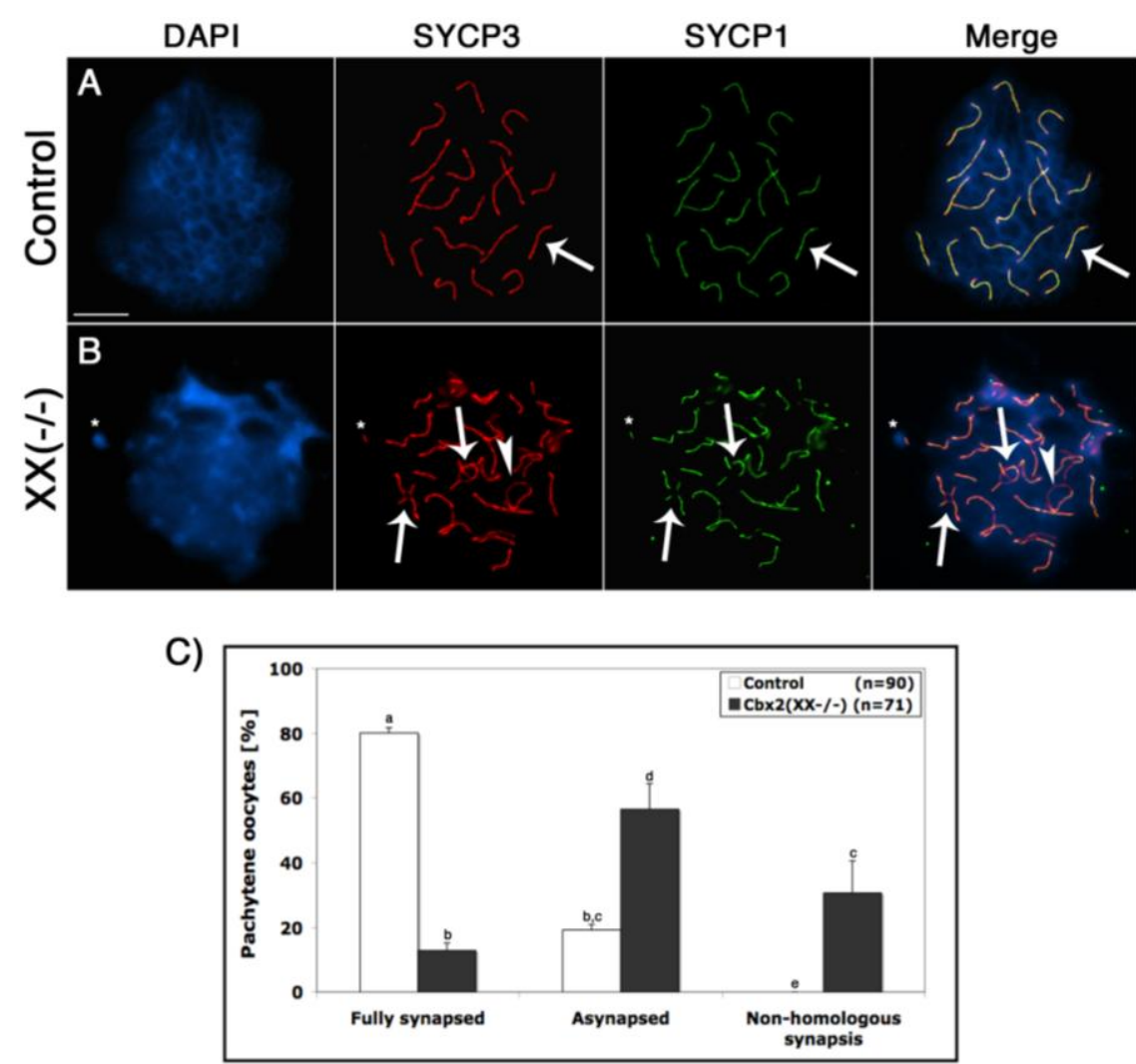

2.3.1. Persistence of DNA Double Strand Breaks and Early Recombination Intermediates at the Pachytene Stage in $\mathrm{Cbx} 2^{(\mathrm{XX}-/-)}$ Oocytes

Initiation of programmed DNA double strand breaks (DSBs) during leptotene stage of meiosis is marked by a striking accumulation of the phosphorylated form of the histone variant $\mathrm{H} 2 \mathrm{AX}(\gamma \mathrm{H} 2 \mathrm{AX})$, which is required for the recruitment of factors involved in the repair of DSBs during chromosome synapsis [30-32]. Following resolution of DSBs at the pachytene stage, persistent $\gamma \mathrm{H} 2 \mathrm{AX}$ marks the majority of asynapsed chromosomes or chromosome segments and its presence in fully synapsed bivalents has been associated with structural chromosome damage [33,34]. Therefore, we set out to determine the patterns of $\gamma \mathrm{H} 2 \mathrm{AX}$ nuclear localization in Cbx2 mutant oocytes at the pachytene and diplotene stage. Our analysis revealed that $\gamma \mathrm{H} 2 \mathrm{AX}$ was undetectable in fully synapsed chromosomes 
in the majority $(87 \%)$ of control oocytes $(n=229)$ at the pachytene stage (Figure 4A, B, I). In contrast, a spectrum of meiotic abnormalities was detected in $C b x 2^{\left(\mathrm{XX}^{-1-}\right)}$ mutant oocytes $(n=162)$. For example, $\gamma \mathrm{H} 2 \mathrm{AX}$ (green) was observed in chromosome bivalents showing full synapsis and/or axial gaps in the synaptonemal complex (red) in $12.3 \%(p<0.05)$ of mutant germ cells (Figure 4C, D and I) consistent with the presence of structural chromosome damage. Moreover, pronounced $\gamma \mathrm{H} 2 \mathrm{AX}$ signals were also detected at asynapsed chromosomes in $56.7 \%(p<0.05)$ of mutant oocytes (Figure $4 \mathrm{I})$. This observation was further substantiated by $\mathrm{X}$ chromosome-specific $\mathrm{FISH}$ analyses indicating the persistence of $\gamma \mathrm{H} 2 \mathrm{AX}$ at $\mathrm{X}$ chromosome univalents in a subpopulation of $\mathrm{Cbx} 2$ deficient oocytes at the diplotene stage (Figure 4E, F). However, we also found evidence for the presence of $\mathrm{X}$ chromosome univalents with no $\gamma \mathrm{H} 2 \mathrm{AX}$ staining suggesting that these chromosomes failed to remain bound by chiasmata at the diplotene stage following initial synapsis and resolution of DSBs at the pachytene stage (Figure 4G, H).

The recombination intermediate Rad51 is a bona fide marker of DSB formation at recombination nodules in meiotic chromosomes during the zygotene stage. However, Rad51 becomes progressively dissociated from crossover sites following resolution of DSBs and homologous chromosome synapsis at the pachytene stage $[35,36]$. As expected, $\operatorname{Rad} 51$ foci were undetectable in the majority of wild type oocytes showing full synapsis of homologous chromosomes at the pachytene stage $(n=101)$, suggesting a timely repair of DSBs (Figure 5, upper panel). In contrast, $>56 \%$ of mutant oocytes $(n=$ 139) presented Rad51 foci (green) associated with asynapsed chromosomes (Figure 5, lower panel, thin arrow). Notably, $>41 \%$ of these mutant oocytes showed additional persistent Rad51 foci at synapsed bivalents exhibiting axial gaps in the synaptonemal complex (arrowhead) as well as segments of incomplete synapsis (bold arrow) demonstrating that loss of $\mathrm{Cbx} 2$ function interferes not only with proper homologous chromosome synapsis but also with the timely resolution of DSBs.

\subsubsection{Activation of the Meiotic Silencing of Unpaired Chromatin (MSUC) Pathway in $\mathrm{Cbx} 2^{(\mathrm{XX}---)}$ Oocytes}

The presence of unrepaired DSBs associated with incomplete chromosome synapsis signals the activation of a specialized transcriptional silencing pathway. Meiotic silencing of unsynapsed chromatin (MSUC) is an essential mechanism that recruits the tumor suppressor protein BRCA1 and the histone variant ubiquitinated $\mathrm{H} 2 \mathrm{~A}$ ( $\mathrm{ubH} 2 \mathrm{~A}$ ) to sites of abnormal chromosome synapsis in both female and male germ cells [25,37]. Intriguingly, recent studies have suggested that members of the Polycomb repressive complex 1 (PRC1) as well as the E3 ubiquitin ligases RNF8/RNF168 are required for monoubiquitination of $\mathrm{H} 2 \mathrm{~A}$ at lysine 119 in somatic cells [38-45]. In order to address whether MSUC is properly initiated in oocytes lacking Cbx2 function, we assessed the sub-nuclear localization patterns of BRCA1 (green) and ubH2A (red) in $C b x 2^{\left(\mathrm{XX}^{-l-}\right)}$ mutant oocytes. While BRCA1 was undetectable in fully synapsed chromosomes of oocytes recovered from control fetuses (Figure 6A, upper panel), $C b x 2^{\left(\mathrm{XX}^{-l-}\right)}$ mutant oocytes showed prominent associations of BRCA1 in one or two fully synapsed bivalents (arrow). In contrast, BRCA1 was also present as small foci on several incompletely synapsed chromosomes (arrowhead) indicating activation of the MSUC response pathway. Similarly, no ubH2A labeling (red) was observed in fully synapsed bivalents of control oocytes at the pachytene or diplotene stage (Figure 6B). In striking contrast, ubH2A (red) was co-localized with asynapsed chromosome axes (green) in the majority of mutant oocytes at the 
pachytene stage (Figure 6C, upper panel, arrows) and also persisted at fully synapsed chromosome bivalents (Supplemental Figure S1) as well as desynapsed chromosome cores during diplotene stage (Figure 6C, lower panel, arrow). These results indicate that loss of $\mathrm{Cbx} 2$ function in the female germline does not preclude activation of the cellular MSUC response. However, evidence suggests that extensive chromosome asynapsis in a subset of mutant oocytes results in focal BRCA1 staining instead of a uniform accumulation of BRCA1 throughout the length of the meiotic chromosome core indicative of an impaired activation of the MSUC response (Supplemental Figure S2), which is in agreement with recent studies indicating that excessive asynapsis depletes the available BRCA1 protein pool leading to an attenuation of the MSUC response [30,46].

Figure 4. Persistence of $\mathrm{H} 2 \mathrm{AX}$ phosphorylation and presence of univalent chromosomes in $C b x 2^{\left(\mathrm{XX}^{-/-}\right)}$oocytes. (A) Late pachytene oocyte obtained from a control $C b \times 2^{(\mathrm{XX}+/+)}$ ovary on day $18.5 \mathrm{pc}$ exhibiting complete chromosome synapsis (20 bivalents). Note the absence of $\gamma \mathrm{H} 2 \mathrm{AX}$ staining; (B) The position of the $\mathrm{X}$ chromosome bivalent (white) is indicated; (C, D) Mutant oocyte exhibiting a chromosome bivalent with axial gaps in the synaptonemal complex decorated by $\gamma \mathrm{H} 2 \mathrm{AX}$ staining (green) suggesting the presence of structural chromosome damage (arrow); (E, F) Persistence of H2AX phosphorylation (green) in $C b x 2^{\left(\mathrm{XX}^{--}\right)}$oocytes showing failure to resolve DSBs at $\mathrm{X}$ chromosome univalents (arrows); $(\mathbf{G}, \mathbf{H}) C b x 2^{(\mathrm{XX}-/-)}$ oocyte at diplotene stage exhibiting $\gamma \mathrm{H} 2 \mathrm{AX}$ staining at asynapsed chromosomes (arrow). Note the presence of $\mathrm{X}$ chromosome univalents and non-homologous associations lacking $\gamma \mathrm{H} 2 \mathrm{AX}$ foci (arrowhead). Synaptonemal complexes are labeled with SYCP3 (red) and DNA is shown in blue. The position of the $\mathrm{X}$ chromosomes is marked with (X); (I) Proportion of mutant oocytes exhibiting abnormal $\gamma \mathrm{H} 2 \mathrm{AX}$ patterns. Scale bars $=10 \mu \mathrm{m}$.

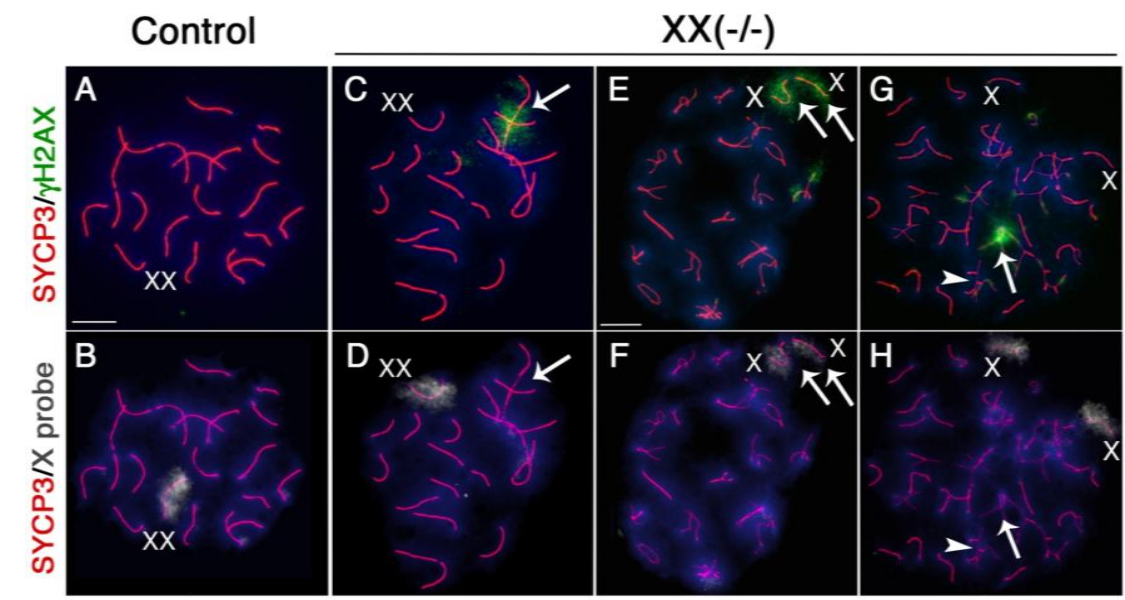

I)

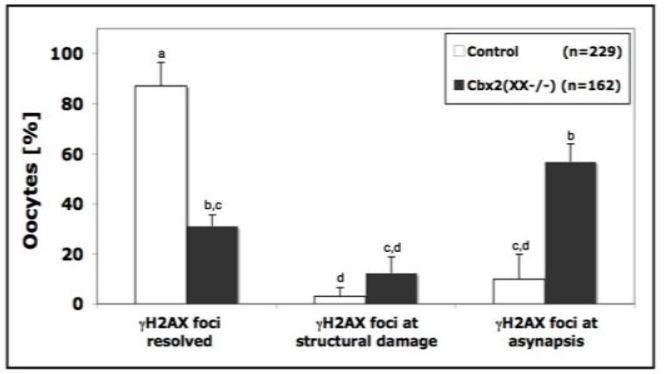


Figure 5. Rad51 foci associate with asynapsed chromosomes and chromosome segments in $C b x 2$ mutant oocytes. Complete meiotic chromosome synapsis in control oocytes is associated with the timely resolution of DSBs and lack of Rad51 foci at the pachytene stage (upper panel). In $C b x 2^{\left(\mathrm{XX}^{-/-}\right)}$mutant oocytes non-homologous and incomplete chromosome synapsis leads to persistence of Rad51 foci (green, arrow, thin arrow) on meiotic chromosome axes (lower panel). Moreover, Rad51 foci are also retained at chromosome cores that appear fully synapsed but exhibit axial gaps on the synaptonemal complex (arrowhead). SYCP3 is shown in red and DNA is shown in blue. Scale bar $=10 \mu \mathrm{m}$.

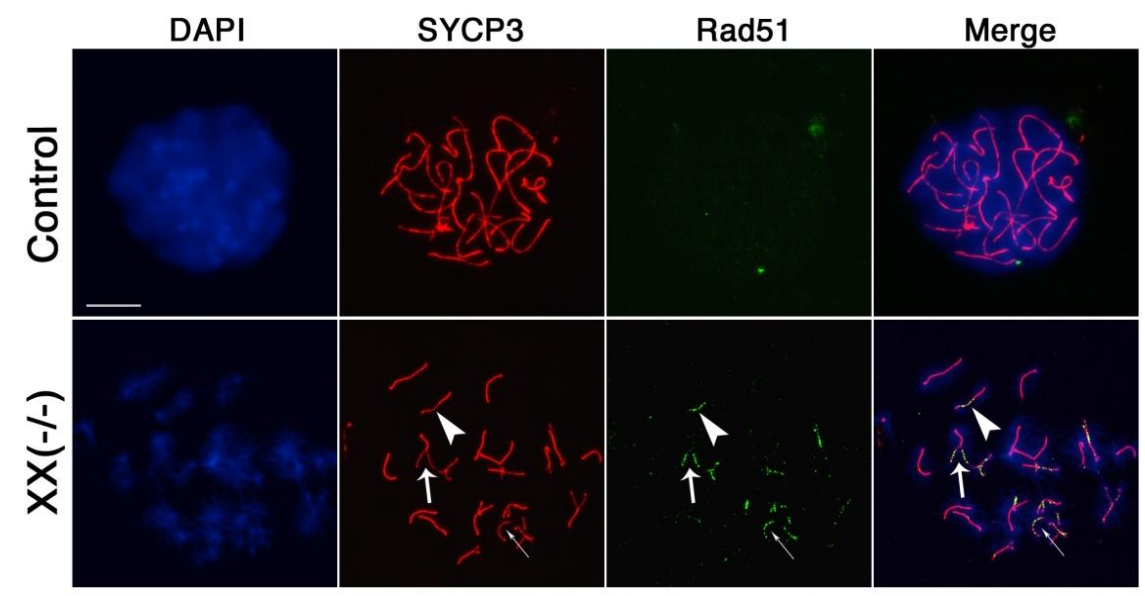

Importantly, together with the patterns of Rad51 localization, our findings indicate that failure to repair DSBs results in the persistence of BRCA1 and ubH2A staining on fully synapsed chromosomes at the diplotene stage. Therefore the association of these markers with fully synapsed chromosomes in this model might be a reflection of structural damage to meiotic chromosomes or alternatively, to the lack of establishment of an intimate synapsis between homologous chromosomes. The patterns of ubH2A localization observed at the pachytene and diplotene stage (Figure 6C, lower panel and Supplemental Figure S1) also indicates that component molecules of the PRC1 complex other than $\mathrm{Cbx} 2$ are involved in establishing histone $\mathrm{H} 2 \mathrm{~A}$ ubiquitination in the female germline.

Finally, we set out to analyze whether the meiotic defects associated with lack of Cbx2 function interferes with the establishment of mature recombination nodules in mutant oocytes. The mismatch repair protein Mlh1 is a marker of crossover formation and is normally loaded onto mature recombination nodules during mid- to late pachytene stage. Analysis of chromosomal distribution patterns of Mlh1 (red) demonstrated that pachytene oocytes obtained from $C b x 2^{\left(\mathrm{XX}^{-/-)}\right.}$mutant fetuses show, similar to control oocytes (arrow, upper panel), one to two Mlh1 foci on each fully synapsed bivalent (Figure 7, lower panel, arrow). As expected, Mlh1 foci were not detectable at asynapsed chromosome univalents in mutant oocytes due to lack of crossover formation (Figure 7, lower panel, arrowhead). These results suggest that formation of chiasmata proceeds seemingly unimpaired in most but not all fully synapsed homologous chromosomes, while chiasmata formation is precluded in the remaining asynapsed univalents in oocytes lacking $\mathrm{Cbx} 2$. 
Figure 6. Activation of meiotic silencing of unsynapsed chromatin (MSUC) in $C b x 2^{(\mathrm{XX}-/-)}$ oocytes. (A) Compared to oocytes isolated from control ovaries (upper panel), $C b x 2^{(\mathrm{XX}-/-)}$ oocytes show prominent BRCA1 labeling (green) at a subset of synapsed chromosome cores (red, arrow), while the majority of incompletely synapsed bivalents show BRCA1 with a focal distribution (arrowheads); (B) The histone modification ubH2A (red) is not detectable in control oocytes at the pachytene (upper panel) or the diplotene (lower panel) stage of meiosis; (C) In $C b x 2^{\left(\mathrm{XX}^{-/-}\right)}$mutant oocytes, ubH2A associates with the chromosome cores (green) of asynapsed meiotic bivalents at the pachytene stage (arrows, upper panel) and persists at these chromosomal domains until the diplotene stage (arrow, lower panel). DNA is shown in blue. Scale bars $=10 \mu \mathrm{m}$.

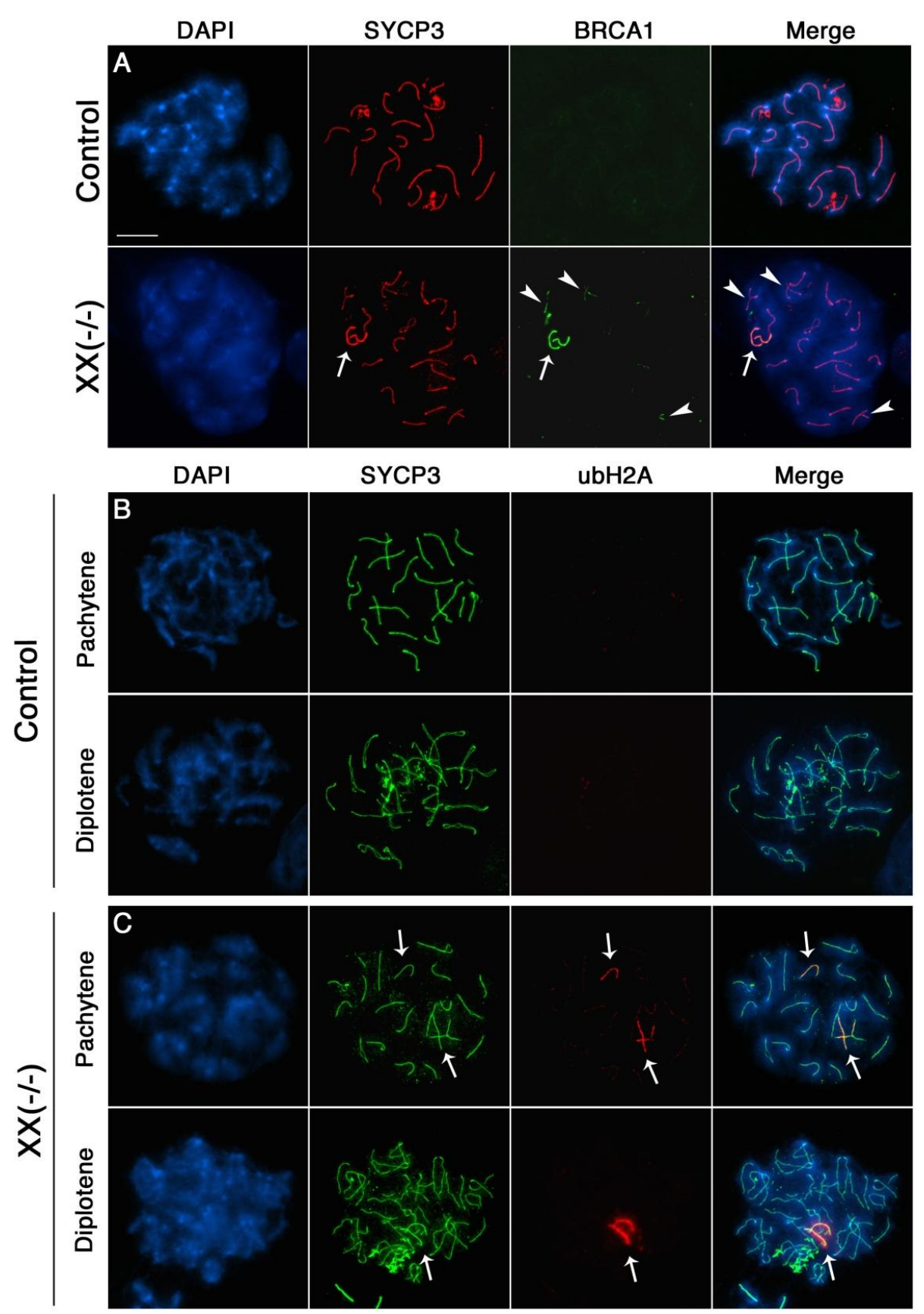


Figure 7. Crossover formation in mutant $C b x 2^{(\mathrm{XX}-1-)}$ oocytes. Control oocytes (upper panel) as well as oocytes recovered from mutant $C b x 2^{(\mathrm{XX}--)}$ fetuses (lower panel) at $18.5 \mathrm{dpc}$ exhibit 1-2 Mlh1 foci (red) per fully synapsed chromosome bivalent (arrows). In contrast, asynapsed meiotic chromosomes in pachytene stage $C b x 2^{\left(\mathrm{XX}^{-l-}\right)}$ oocytes lack Mlh1 foci due to failure to establish homologous recombination sites (arrowhead). DNA is shown in blue. Scale bars $=10 \mu \mathrm{m}$.

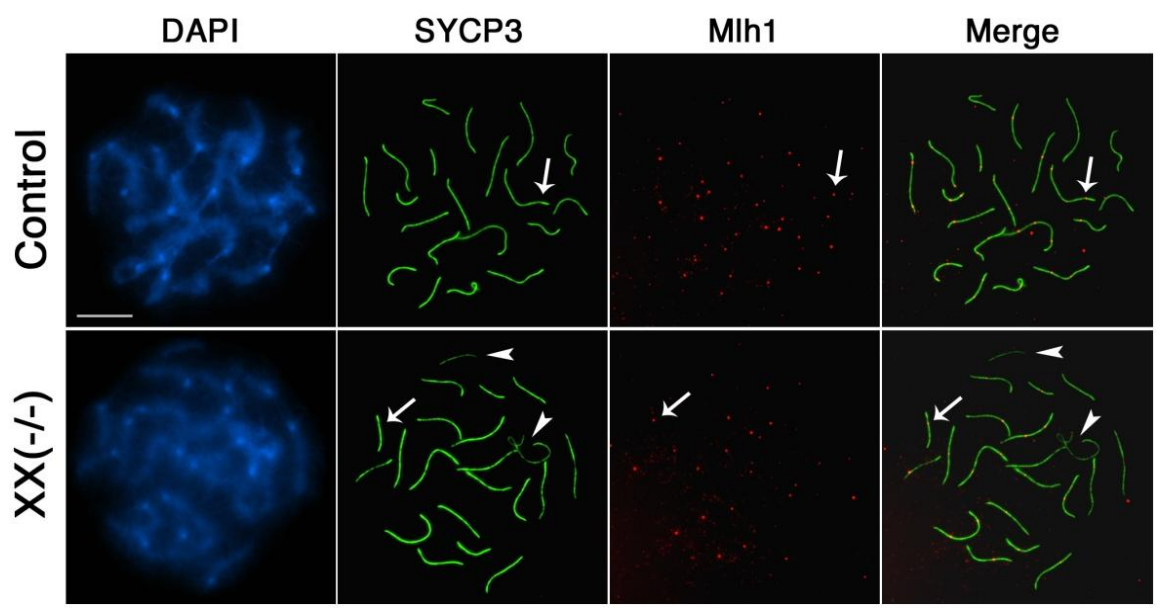

Induction of DSBs is tightly linked to histone $\mathrm{H} 2 \mathrm{~A}$ phosphorylation $(\gamma \mathrm{H} 2 \mathrm{AX})[31,37]$ as well as to the loading of recombination intermediates such as Rad51, Mre11 [47], Msh2 [48] and Dmc1 [35,49] at early recombination nodules. The patterns of $\gamma \mathrm{H} 2 \mathrm{AX}$ and Rad51 staining in $\mathrm{Cb} x 2^{(\mathrm{XX}-1-)}$ mutant oocytes indicate that induction of DSBs and loading of recombination intermediates occurs normally in this model. However, failure to resolve DSBs results in recombination errors and structural damage to chromosomes and may interfere with the formation of chiasmata following homologous chromosome synapsis [32,36,47-52]. Therefore, the presence of such meiotic defects may predispose $\mathrm{Cbx} 2$ deficient oocytes to the formation of chromosome univalents at the diplotene stage.

Our study has uncovered a novel role for the Polycomb group protein Cbx2 in meiosis through the maintenance of genome stability during this critical developmental window. Yet, precocious meiosis in testicular germ cells from $C b x 2^{(\mathrm{XY}-/-)}$ mutant fetuses with bilateral testes as well as sex reversed mutants exhibiting a unilateral testis grant unexpected insight into male meiosis onset. Importantly, our results reveal a novel role for $\mathrm{Cbx} 2$ protein in meiotic chromosome synapsis in mammalian oocytes.

Little is known regarding the function of Polycomb group proteins in mammalian germ cells. Nevertheless, PcG proteins have been shown to play important roles in the maintenance of chromatin structure and organization during developmental transitions through the establishment of a characteristic and heritable epigenetic landscape. Accordingly, these highly conserved proteins associate in large multi-protein complexes that are capable of altering the nucleosomal composition through the initiation of modifications at specific histone tails, such as H3K27me3 [53,54]. Cbx2 is thought to act as transcriptional regulator at developmental target genes in the context of such complexes [29], although our understanding of the specificity of the particular targeting mechanism is limited. Previous studies have shown that $\mathrm{Cbx} 2$ expression, along with other components of PRC1 (Bmi1 and Rae28), is detectable between day 8.5 and $18.5 \mathrm{dpc}$ in whole embryo extracts and is an 
abundant protein in the adult ovary and testis [55]. Cbx 2 is known to localize to facultative heterochromatin of the inactive $\mathrm{X}$ chromosome [27,28], to centromeric heterochromatin at metaphase in fibroblasts [29] and to Hoechst-bright chromocenters in embryonic stem cells [28], while it is excluded from the nuclear macrochromatin domain forming the $\mathrm{XY}$ body in mouse spermatocytes [56].

PcG interactions with chromatin domains have long been attributed to the chromodomain, a conserved feature common to all Chromobox proteins [57]. However, using bimolecular fluorescence complementation (BiFC) analysis, a recent study indicates that the chromodomain as well as the chromobox of Cbx proteins might be dispensable for DNA binding as such [28]. Interestingly, Cbx2 differs from all other Cbx proteins by a newly identified protein domain, the AT-Hook [58]. AT-Hook motifs are conserved domains found in many DNA-binding proteins and are thought to enhance protein interactions with AT-rich chromatin domains [59]. According to this model, Cbx2 may promote chromatin remodeling directly through interactions with the minor groove of AT-rich satellite DNA sequences, while simultaneous binding of the $N$-terminal Cbx2 chromodomain to specific histone tails (H3K27me3, H3K4me3, H3K9ac) within the adjoining nucleosome could complete the establishment of the remodeled chromatin status $[28,58]$.

Importantly, chromatin remodeling processes are essential for homologous chromosome pairing, synapsis and proper chromosome segregation during meiosis in a wide array of organisms from plants [60] to mammals [15,61-65]. The phenotype observed in fetal oocytes lacking Cbx2 might suggest a functional role for $\mathrm{Cbx} 2$ in chromatin remodeling required for the establishment and/or repair of DSBs, homologous chromosome pairing or sister chromatid cohesion between homologous chromosomes. Interestingly, several chromodomain and PcG-associated proteins have previously been demonstrated to play a role in meiotic sister chromatid cohesion in Drosophila [66], DSB repair in mammals [67,68] as well as locus-specific imprinting during meiosis in fission yeast [69]. However, further analyses are necessary to identify the precise mechanism of action of $\mathrm{Cbx} 2$ in conferring genome stability during meiosis in the female germline.

\section{Experimental Section}

\subsection{Mice}

All animal experiments were approved by the institutional animal use and care committee of the University of Pennsylvania according to National Institutes of Health guidelines.

Mice heterozygous for a targeted deletion of $C b x 2$ (C.129P2-Cbx $\left.2^{\mathrm{tm} 1 \mathrm{Cim}} / \mathrm{J}\right)[23]$ were obtained from the Jackson Laboratory (Bar Harbor, ME). To obtain fetuses carrying a homozygous null mutation $\left(C b x 2^{(--)}\right)$, heterozygous mating pairs were set up and fetal gonads were collected on day $18.5 \mathrm{pc}$. Genotyping of $C b x 2^{(-)}$mice was conducted according to the Jackson Laboratory's genotyping protocol for $\mathrm{Cbx} 2^{\mathrm{tm} 1 \mathrm{Cim}}$, version 1.1 using the following primer pairs: "Cbx2-fwd AAC CGG AAG AGA GGC AAG AG”; "Cbx2-rev CCT GAA GGA GCA ACA AGA AAG”; "Neo-rev AGG TGA GAT GAC AGG AGA TC". Genomic tail DNA was extracted by using the DNeasy Blood and Tissue Kit (QIAGEN Sciences, Germantown, MD) following manufacturer's instructions. The PCR conditions to determine the genotype were as follows: $94{ }^{\circ} \mathrm{C}$ for $3 \mathrm{~min} ; 38$ cycles of $94{ }^{\circ} \mathrm{C}$ for $30 \mathrm{~s}$, 
$58{ }^{\circ} \mathrm{C}$ for $1 \mathrm{~min}$ and $72{ }^{\circ} \mathrm{C}$ for $1 \mathrm{~min}$; followed by $72{ }^{\circ} \mathrm{C}$ for $10 \mathrm{~min}$, and maintained at $4{ }^{\circ} \mathrm{C}$ until gel electrophoresis (Bio-Rad Laboratories, Hercules, CA). The chromosomal sex of each fetus was analyzed in parallel using the primer pair "Sry-fwd CTG TGT AGG ATC TTC AAT CTC T" and "Sry-rev GTG GTG AGA GGC ACA AGT TGG C" specifically amplifying a genomic region within the Y chromosomal SRY gene.

\subsection{Histology and Analysis of Meiotic Configurations in $\mathrm{Cbx} 2^{(--)}$Fetal Germ Cells}

Fetal gonads were dissected from control and $C b x 2^{(--)}$fetuses on day $18 \mathrm{pc}$ and immediately fixed in Bouin's solution (Sigma, St. Louis, MI). Following overnight fixation, the gonads were washed in PBS solution and processed for paraffin embedding and sectioning according to standard procedures. $5 \mu \mathrm{m}$ serial sections were stained with $\mathrm{H} \& \mathrm{E}$ before microscopy and image acquisition. Fetal gonads recovered from fetuses on day $18.5 \mathrm{pc}$ were also processed for the analysis of chromosome synapsis and meiotic recombination proteins on surface spread germ cells as described previously [70]. Briefly, gonads were dissected and transferred to a hypotonic solution containing $1 \%$ sodium citrate for $20 \mathrm{~min}$, before spreading of meiotic configurations onto glass slides and fixation in a solution of $1 \%$ paraformaldehyde, $0.1 \%$ Triton X 100 .

\subsection{Immunochemistry}

Unless otherwise specified, all primary antibody incubations were conducted overnight at $4{ }^{\circ} \mathrm{C}$. The extend of meiotic chromosome synapsis in control and mutant germ cells was determined by immunochemical detection of the lateral elements of the synaptonemal complex protein SYCP3 using a 1:1000 dilution of a rabbit anti-SYCP3 antibody (abcam, Cambridge, MA). An anti-phosphohistone H2AX (Ser-139) antibody (Upstate, Charlottesville, VA) was used at a 1:500 dilution. The type of meiotic configuration present in control and mutant oocytes at the pachytene stage was analyzed by simultaneous staining of the central element of the synaptonemal complex with a rabbit anti-SYCP1 antibody (1:500) and a guinea pig anti-SYCP3 at a 1:250 dilution [71]. Antibodies directed against BRCA1 (goat polyclonal, Santa Cruz, CA) and ubH2A (mouse monoclonal, clone E6C5, Millipore, Billerica, MA) were used at a dilution of 1:400. The mouse monoclonal anti-Mlh1 (BD Pharmingen) and mouse polyclonal anti-Rad51 (Oncogene) antibodies were both used following an overnight incubation at $37{ }^{\circ} \mathrm{C}$ at a 1:50 dilution in combination with a rabbit anti-SYCP3 antibody (1:250). Immunodetection was performed using appropriate Alexa Fluor-conjugated secondary antibodies (Molecular Probes, Eugene, Oregon, USA) at a dilution of 1:1000 for $2 \mathrm{~h}$ at room temperature.

Following immunochemistry, slides were counterstained with $7 \mu \mathrm{L}$ of antifading medium supplemented with DAPI (Vectashield; Vector Laboratories, Burlingame, CA). Epifluorescence analysis of meiotic chromosomes was conducted on a DMRX/E microscope (Leica Microsystems) using a 100x objective. Images were captured with a Leica DFC 350F camera using Openlab 3.1.7. software (PerkinElmer) and image processing was performed using Photoshop 2.0 (Adobe) for linear adjustments and cropping of fluorescent images. No gamma adjustments were made. 


\subsection{Fluorescence in situ Hybridization (FISH)}

The position of the sex chromosomes in control and mutant germ cells was determined by Immuno-FISH analysis following immunochemistry on the same slide using a FITC-conjugated X and a Cy3-conjugated $\mathrm{Y}$ chromosome paint (STARFISH, Cambio) according to manufacturer's specifications. Briefly, surface spread interphase nuclei and metaphase chromosomes were denatured in $70 \%$ formamide (VWR International Ltd., Poole, UK) in $2 \times \mathrm{SSC}$ at $80{ }^{\circ} \mathrm{C}$ for $10 \mathrm{~min}$ and subsequently chilled in ice-cold $70 \%$ ethanol for $5 \mathrm{~min}$. The $\mathrm{X}$ and $\mathrm{Y}$ chromosome-specific probes were denatured for $10 \mathrm{~min}$ at $85{ }^{\circ} \mathrm{C}$, respectively, and incubated at $40{ }^{\circ} \mathrm{C}$ for $1 \mathrm{~h}$. Overnight hybridization was carried out in a humidified chamber at $40{ }^{\circ} \mathrm{C}$ and stringency washes were conducted in a solution containing $50 \%$ formamide in $2 \times \mathrm{SSC}$ as previously described $[64,72]$. Co-localization of a fully synapsed bivalent with the signal provided by the $\mathrm{X}$ chromosome-specific probe was considered indicative of complete homologous pairing of the $\mathrm{X}$ bivalent in $\mathrm{XX}$ oocytes at the pachytene stage.

\subsection{Statistical Analysis}

Data presented as percentage values were analyzed by one-way analysis of variance (ANOVA) following arcsine transformation. Comparison of all pairs was conducted by the Tukey-Kramer HSD or Student's t-test using JMP Start Statistics (SAS Institute Inc., Cary, NC). Variation among individual replicates is indicated as the standard deviation (s.d.). Differences were considered significant when $P<0.05$ and are indicated by different superscripts.

\section{Conclusions}

The Cbx 2 protein is expressed in the human embryonic gonadal ridge at seven weeks of gestation, consistent with its prominent role in early gonadal growth and differentiation [73]. Importantly, lack of Cbx2 function results in male to female sex reversal [18,21]. However, our study revealed major differences in the sex reversal phenotype according to the genetic background in mice. The milder phenotype observed in the BALB/C model allowed for the identification of a critical role for Cbx 2 in germ cell development. Our studies uncovered a previously unrecognized role for $\mathrm{Cbx} 2$ in maintaining the pre-meiotic arrest in male germ cells and suggest that germ cell-specific chromatin modifications and structure may be an important component to confer specificity to the otherwise pleiotropic effects of RA on gonadal differentiation. Importantly, our studies uncovered a critical role for $\mathrm{Cbx} 2$ in homologous chromosome synapsis and chromosome stability in the female germline. These results may have important implications to understand the mechanisms involved in previously reported cases of pediatric patients exhibiting male to female sex reversal [20].

\section{Acknowledgements}

We are grateful to Maria M. Viveiros for stimulating discussions and critical reading of the manuscript. This study was supported by a grant from the National Institutes of Health (NICHD): 2RO1-HDO42740 to Rabindranath De La Fuente. 


\section{References}

1. McLaren, A. Primordial germ cells in the mouse. Dev. Biol. 2003, 262, 1-15.

2. Baltus, A.E.; Menke, D.B.; Hu, Y.-C.; Goodheart, M.L.; Carpenter, A.E.; de Rooij, D.G.; Page, D.C. In germ cells of mouse embryonic ovaries, the decision to enter meiosis precedes premeiotic DNA replication. Nat. Genet. 2006, 38, 1430-1434.

3. Bowles, J.; Knight, D.; Smith, C.; Wilhelm, D.; Richman, J.; Mamiya, S.; Yashiro, K.; Chawengsaksophak, K.; Wilson, M.J.; Rossant, J.; Hamada, H.; Koopman, P. Retinoid signaling determines germ cell fate in mice. Science 2006, 312, 596-600.

4. Koubova, J.; Menke, D.B.; Zhou, Q.; Capel, B.; Griswold, M.D.; Page, D.C. Retinoic acid regulates sex-specific timing of meiotic initiation in mice. Proc. Natl. Acad. Sci. USA 2006, 103, 2474-2479.

5. Lin, Y.; Gill, M.E.; Koubova, J.; Page, D.C. Germ Cell-Intrinsic and -Extrinsic Factors Govern Meiotic Initiation in Mouse Embryos. Science 2008, 322, 1685-1687.

6. Bowles, J.; Koopman, P. Retinoic acid, meiosis and germ cell fate in mammals. Development 2007, 134, 3401-3411.

7. Wang, N.; Tilly, J. Epigenetic status determines germ cell meiotic commitment in embryonic and postnatal mammalian gonads. Cell Cycle 2010, 9, 339-349.

8. Ohinata, Y.; Payer, B.; O'Carroll, D.; Ancelin, K.; Ono, Y.; Sano, M.; Barton, S.C.; Obukhanych, T.; Nussenzweig, M.; Tarakhovsky, A.; Saitou, M.; Surani, M.A. Blimp1 is a critical determinant of the germ cell lineage in mice. Nature 2005, 436, 207-213.

9. Ohinata, Y.; Seki, Y.; Payer, B.; O'Carroll, D.; Surani, M.A.; Saitou, M. Germline recruitment in mice: a genetic program for epigenetic reprogramming. Ernst Schering Res. Found. Workshop 2006, 143-174.

10. Ancelin, K.; Lange, U.C.; Hajkova, P.; Schneider, R.; Bannister, A.J.; Kouzarides, T.; Surani, M.A. Blimp1 associates with Prmt5 and directs histone arginine methylation in mouse germ cells. Nat. Cell Biol. 2006, 8, 623-630.

11. Hajkova, P.; Ancelin, K.; Waldmann, T.; Lacoste, N.; Lange, U.C.; Cesari, F.; Lee, C.; Almouzni, G.; Schneider, R.; Surani, M.A. Chromatin dynamics during epigenetic reprogramming in the mouse germ line. Nature 2008, 452, 877-881.

12. Hayashi, K.; Yoshida, K.; Matsui, Y. A histone H3 methyltransferase controls epigenetic events required for meiotic prophase. Nature 2005, 438, 374-378.

13. Matsui, Y.; Hayashi, K. Epigenetic regulation for the induction of meiosis. Cell Mol. Life Sci. 2007, 64, 257-262.

14. Surani, M.A.; Hayashi, K.; Hajkova, P. Genetic and epigenetic regulators of pluripotency. Cell 2007, 128, 747-762.

15. Peters, A.H.; O'Carroll, D.; Scherthan, H.; Mechtler, K.; Sauer, S.; Schofer, C.; Weipoltshammer, K.; Pagani, M.; Lachner, M.; Kohlmaier, A.; Opravil, S.; Doyle, M.; Sibilia, M.; Jenuwein, T. Loss of the Suv39h histone methyltransferases impairs mammalian heterochromatin and genome stability. Cell 2001, 107, 323-337.

16. Tachibana, M.; Nozaki, M.; Takeda, N.; Shinkai, Y. Functional dynamics of H3K9 methylation during meiotic prophase progression. Embo J. 2007, 26, 3346-3359. 
17. Bracken, A.P.; Helin, K. Polycomb group proteins: navigators of lineage pathways led astray in cancer. Nat. Rev. Cancer 2009, 9, 773-784.

18. Core, N.; Bel, S.; Gaunt, S.J.; Aurrand-Lions, M.; Pearce, J.; Fisher, A.; Djabali, M. Altered cellular proliferation and mesoderm patterning in Polycomb-M33-deficient mice. Development 1997, 124, 721-729.

19. Bel-Vialar, S.; Core, N.; Terranova, R.; Goudot, V.; Boned, A.; Djabali, M. Altered retinoic acid sensitivity and temporal expression of Hox genes in polycomb-M33-deficient mice. Dev. Biol. 2000, 224, 238-249.

20. Biason-Lauber, A.; Konrad, D.; Meyer, M.; deBeaufort, C.; Schoenle, E.J. Ovaries and Female Phenotype in a Girl with 46, XY Karyotype and Mutations in the CBX2 Gene. Am. J. Hum. Genet. 2009, 84, 658-663.

21. Katoh-Fukui, Y.; Tsuchiya, R.; Shiroishi, T.; Nakahara, Y.; Hashimoto, N.; Noguchi, K.; Higashinakagawa, T. Male-to-female sex reversal in M33 mutant mice. Nature 1998, 393, 688-692.

22. Munger, S.C.; Aylor, D.L.; Syed, H.A.; Magwene, P.M.; Threadgill, D.W.; Capel, B. Elucidation of the transcription network governing mammalian sex determination by exploiting strain-specific susceptibility to sex reversal. Genes Dev. 2009, 23, 2521-2536.

23. Core, N.; Joly, F.; Boned, A.; Djabali, M. Disruption of E2F signaling suppresses the INK4a-induced proliferative defect in M33-deficient mice. Oncogene 2004, 23, 7660-7668.

24. Eicher, E.M.; Washburn, L.L.; Whitney, J.B.; Morrow, K.E. Mus poschiavinus Y Chromosome in the C57BL/6J Murine Genome Causes Sex Reversal. Science 1982, 217, 535-537.

25. Baarends, W.; Wassenaar, E.; van der Laan, R.; Hoogerbrugge, J.; Sleddens-Linkels, E.; Hoeijmakers, J.; de Boer, P.; Grootegoed, J. Silencing of unpaired chromatin and histone H2A ubiquitination in mammalian meiosis. Mol. Cell. Biol. 2005, 25, 1041-1053.

26. Okada, A.; Aoki, Y.; Kushima, K.; Kurihara, H.; Bialer, M.; Fujiwara, M. Polycomb homologs are involved in teratogenicity of valproic acid in mice. Birth Defects Res. Part A: Clin. Mol. Teratol. 2004, 70, 870-879.

27. Bernstein, E.; Duncan, E.; Masui, O.; Gil, J.; Heard, E.; Allis, C. Mouse polycomb proteins bind differentially to methylated histone H3 and RNA and are enriched in facultative heterochromatin. Mol. Cell. Biol. 2006, 26, 2560-2569.

28. Vincenz, C.; Kerppola, T.K. Different polycomb group CBX family proteins associate with distinct regions of chromatin using nonhomologous protein sequences. Proc. Natl. Acad. Sci. USA 2008, 105, 16572-16577.

29. Wang, G.; Horsley, D.; Ma, A.; Otte, A.P.; Hutchings, A.; Butcher, G.W.; Singh, P.B. M33, a mammalian homologue of Drosophila Polycomb localises to euchromatin within interphase nuclei but is enriched within the centromeric heterochromatin of metaphase chromosomes. Cytogenet. Cell Genet. 1997, 78, 50-55.

30. Mahadevaiah, S.K.; Bourc'his, D.; de Rooij, D.G.; Bestor, T.H.; Turner, J.M.; Burgoyne, P.S. Extensive meiotic asynapsis in mice antagonises meiotic silencing of unsynapsed chromatin and consequently disrupts meiotic sex chromosome inactivation. J. Cell Biol. 2008, 182, 263-276. 
31. Mahadevaiah, S.K.; Turner, J.M.; Baudat, F.; Rogakou, E.P.; de Boer, P.; Blanco-Rodriguez, J.; Jasin, M.; Keeney, S.; Bonner, W.M.; Burgoyne, P.S. Recombinational DNA double-strand breaks in mice precede synapsis. Nat. Genet. 2001, 27, 271-276.

32. Burgoyne, P.; Mahadevaiah, S.; Turner, J. The consequences of asynapsis for mammalian meiosis. Nat. Rev. Genet. 2009, 10, 207-216.

33. Wang, H.; Hoog, C. Structural damage to meiotic chromosomes impairs DNA recombination and checkpoint control in mammalian oocytes. J. Cell Biol. 2006, 173, 485-495.

34. Schimenti, J. Synapsis or silence. Nat. Genet. 2005, 37, 11-13.

35. Moens, P.; Kolas, N.; Tarsounas, M.; Marcon, E.; Cohen, P.; Spyropoulos, B. The time course and chromosomal localization of recombination-related proteins at meiosis in the mouse are compatible with models that can resolve the early DNA-DNA interactions without reciprocal recombination. J. Cell Sci. 2002, 115, 1611-1622.

36. Bannister, L.; Schimenti, J. Homologous recombinational repair proteins in mouse meiosis. Cytogenet. Genome Res. 2004, 107, 191-200.

37. Turner, J.; Mahadevaiah, S.; Fernandez-Capetillo, O.; Nussenzweig, A.; Xu, X.; Deng, C.; Burgoyne, P. Silencing of unsynapsed meiotic chromosomes in the mouse. Nat. Genet. 2005, $37,41-47$.

38. Zaaroor-Regev, D.; de Bie, P.; Scheffner, M.; Noy, T.; Shemer, R.; Heled, M.; Stein, I.; Pikarsky, E.; Ciechanover, A. Regulation of the polycomb protein Ring1B by self-ubiquitination or by E6-AP may have implications to the pathogenesis of Angelman syndrome. Proc. Natl. Acad. Sci. USA 2010, 107, 6788-6793.

39. Fang, J.; Chen, T.; Chadwick, B.; Li, E.; Zhang, Y. Ring1b-mediated H2A ubiquitination associates with inactive $\mathrm{X}$ chromosomes and is involved in initiation of $\mathrm{X}$ inactivation. J. Biol. Chem. 2004, 279, 52812-52815.

40. Wang, H.; Wang, L.; Erdjument-Bromage, H.; Vidal, M.; Tempst, P.; Jones, R.S.; Zhang, Y. Role of histone H2A ubiquitination in Polycomb silencing. Nature 2004, 431, 873-878.

41. Cao, R.; Tsukada, Y.-I.; Zhang, Y. Role of Bmi-1 and Ring1A in H2A Ubiquitylation and Hox Gene Silencing. Mol. Cell 2005, 20, 845-854.

42. de Napoles, M.; Mermoud, J.E.; Wakao, R.; Tang, Y.A.; Endoh, M.; Appanah, R.; Nesterova, T.B.; Silva, J.; Otte, A.P.; Vidal, M.; Koseki, H.; Brockdorff, N. Polycomb group proteins Ring1A/B link ubiquitylation of histone $\mathrm{H} 2 \mathrm{~A}$ to heritable gene silencing and $\mathrm{X}$ inactivation. Dev. Cell 2004, 7, 663-676.

43. Elderkin, S.; Maertens, G.N.; Endoh, M.; Mallery, D.L.; Morrice, N.; Koseki, H.; Peters, G.; Brockdorff, N.; Hiom, K. A Phosphorylated Form of Mel-18 Targets the Ring1B Histone H2A Ubiquitin Ligase to Chromatin. Mol. Cell 2007, 28, 107-120.

44. Huen, M.S.Y.; Grant, R.; Manke, I.; Minn, K.; Yu, X.; Yaffe, M.B.; Chen, J. RNF8 Transduces the DNA-Damage Signal via Histone Ubiquitylation and Checkpoint Protein Assembly. Cell 2007, 131, 901-914.

45. Mailand, N.; Bekker-Jensen, S.; Faustrup, H.; Melander, F.; Bartek, J.; Lukas, C.; Lukas, J. RNF8 Ubiquitylates Histones at DNA Double-Strand Breaks and Promotes Assembly of Repair Proteins. Cell 2007, 131, 887-900. 
46. Kouznetsova, A.; Wang, H.; Bellani, M.; Camerini-Otero, R.D.; Jessberger, R.; Hoog, C. BRCA1-mediated chromatin silencing is limited to oocytes with a small number of asynapsed chromosomes. J. Cell Sci. 2009, 122, 2446-2452.

47. Cherry, S.M.; Adelman, C.A.; Theunissen, J.W.; Hassold, T.J.; Hunt, P.A.; Petrini, J.H. The Mre11 complex influences DNA repair, synapsis, and crossing over in murine meiosis. Curr. Biol. 2007, 17, 373-378.

48. Paul, C.; Povey, J.E.; Lawrence, N.J.; Selfridge, J.; Melton, D.W.; Saunders, P.T. Deletion of genes implicated in protecting the integrity of male germ cells has differential effects on the incidence of DNA breaks and germ cell loss. PLOS ONE 2007, 2, e989.

49. Tarsounas, M.; Morita, T.; Pearlman, R.E.; Moens, P.B. Rad51 and Dmc1 Form Mixed Complexes Associated with Mouse Meiotic Chromosome Cores and Synaptonemal Complexes. J. Cell Biol. 1999, 147, 207-220.

50. Burgoyne, P.; Mahadevaiah, S.; Turner, J. The management of DNA double-strand breaks in mitotic $\mathrm{G}(2)$, and in mammalian meiosis viewed from a mitotic $\mathrm{G}(2)$ perspective. Bioessays 2007, 29, 974-986.

51. Pittman, D.; Cobb, J.; Schimenti, K.; Wilson, L.; Cooper, D.; Brignull, E.; Handel, M.; Schimenti, J. Meiotic prophase arrest with failure of chromosome synapsis in mice deficient for Dmc1, a germline-specific RecA homolog. Mol. Cell 1998, 1, 697-705.

52. Yoshida, K.; Kondoh, G.; Matsuda, Y.; Habu, T.; Nishimune, Y.; Morita, T. The Mouse RecA-like Gene Dmc1 Is Required for Homologous Chromosome Synapsis during Meiosis. Mol. Cell 1998, 1, 707-718.

53. Simon, J.A.; Kingston, R.E. Mechanisms of Polycomb gene silencing: knowns and unknowns. Nat. Rev. Mol. Cell. Biol. 2009, 10, 697-708.

54. Muller, J.; Verrijzer, P. Biochemical mechanisms of gene regulation by polycomb group protein complexes. Curr. Opin. Genet. Dev. 2009, 19, 150-158.

55. Hashimoto, N.; Brock, H.W.; Nomura, M.; Kyba, M.; Hodgson, J.; Fujita, Y.; Takihara, Y.; Shimada, K.; Higashinakagawa, T. RAE28, BMI1, and M33 Are Members of Heterogeneous Multimeric Mammalian Polycomb Group Complexes. Biochem. Biophys. Res. Comm. 1998, 245, 356-365.

56. Takada, Y.; Isono, K.; Shinga, J.; Turner, J.M.; Kitamura, H.; Ohara, O.; Watanabe, G.; Singh, P.B.; Kamijo, T.; Jenuwein, T.; Burgoyne, P.S.; Koseki, H. Mammalian Polycomb Scmh1 mediates exclusion of Polycomb complexes from the XY body in the pachytene spermatocytes. Development 2007, 134, 579-590.

57. Paro, R.; Hogness, D.S. The Polycomb protein shares a homologous domain with a heterochromatin-associated protein of Drosophila. Proc. Natl. Acad. Sci. USA 1991, 88, 263-267.

58. Senthilkumar, R.; Mishra, R. Novel motifs distinguish multiple homologues of Polycomb in vertebrates: expansion and diversification of the epigenetic toolkit. BMC Genomics 2009, 10, 549.

59. Aravind, L.; Landsman, D. AT-hook motifs identified in a wide variety of DNA-binding proteins. Nucleic Acids Res. 1998, 26, 4413-4421.

60. Colas, I.; Shaw, P.; Prieto, P.; Wanous, M.; Spielmeyer, W.; Mago, R.; Moore, G. Effective chromosome pairing requires chromatin remodeling at the onset of meiosis. Proc. Natl. Acad. Sci. USA 2008, 105, 6075-6080. 
61. Webster, K.; O’Bryan, M.; Fletcher, S.; Crewther, P.; Aapola, U.; Craig, J.; Harrison, D.; Aung, H.; Phutikanit, N.; Lyle, R.; Meachem, S.; Antonarakis, S.; de Kretser, D.; Hedger, M.; Peterson, P.; Carroll, B.; Scott, H. Meiotic and epigenetic defects in Dnmt3L-knockout mouse spermatogenesis. Proc. Natl. Acad. Sci. USA 2005, 102, 4068-4073.

62. Bourc'his, D.; Bestor, T.H. Meiotic catastrophe and retrotransposon reactivation in male germ cells lacking Dnmt3L. Nature 2004, 431, 96-99.

63. Dantzer, F.; Mark, M.; Quenet, D.; Scherthan, H.; Huber, A.; Liebe, B.; Monaco, L.; Chicheportiche, A.; Sassone-Corsi, P.; de Murcia, G.; Menissier-de Murcia, J. Poly(ADP-ribose) polymerase-2 contributes to the fidelity of male meiosis I and spermiogenesis. Proc. Natl. Acad. Sci. USA. 2006, 103, 14854-14859.

64. De La Fuente, R.; Baumann, C.; Fan, T.; Schmidtmann, A.; Dobrinski, I.; Muegge, K. Lsh is required for meiotic chromosome synapsis and retrotransposon silencing in female germ cells. Nat. Cell. Biol. 2006, 8, 1448-1454.

65. Miyagishima, H.; Isono, K.; Fujimura, Y.; Iyo, M.; Takihara, Y.; Masumoto, H.; Vidal, M.; Koseki, H. Dissociation of mammalian Polycomb-group proteins, Ring1B and Rae28/Ph1, from the chromatin correlates with configuration changes of the chromatin in mitotic and meiotic prophase. Histochem. Cell Biol. 2003, 120, 111-119.

66. Balicky, E.; Young, L.; Orr-Weaver, T.; Bickel, S. A proposed role for the Polycomb group protein dRING in meiotic sister-chromatid cohesion. Chromosoma 2004, 112, 231-239.

67. Sharma, G.G.; So, S.; Gupta, A.; Kumar, R.; Cayrou, C.; Avvakumov, N.; Bhadra, U.; Pandita, R.K.; Porteus, M.H.; Chen, D.J.; Cote, J.; Pandita, T.K. MOF and Histone H4 Acetylation at Lysine 16 Are Critical for DNA Damage Response and Double-Strand Break Repair. Mol. Cell. Biol. 2010, 30, 3582-3595.

68. Wu, S.; Hu, Y.-C.; Liu, H.; Shi, Y. Loss of YY1 Impacts the Heterochromatic State and Meiotic Double-Strand Breaks during Mouse Spermatogenesis. Mol. Cell. Biol. 2009, 29, 6245-6256.

69. Nakayama, J.; Klar, A.; Grewal, S. A chromodomain protein, Swi6, performs imprinting functions in fission yeast during mitosis and meiosis. Cell 2000, 101, 307-317.

70. Libby, B.; De La Fuente, R.; O’Brien, M.; Wigglesworth, K.; Cobb, J.; Inselman, A.; Eaker, S.; Handel, M.; Eppig, J.; Schimenti, J. The mouse meiotic mutation meil disrupts chromosome synapsis with sexually dimorphic consequences for meiotic progression. Dev. Biol. 2002, 242, 174-187.

71. Yuan, L.; Liu, J.G.; Hoja, M.R.; Wilbertz, J.; Nordquist, K.; Hoog, C. Female germ cell aneuploidy and embryo death in mice lacking the meiosis-specific protein SCP3. Science 2002, 296, 115-118.

72. De La Fuente, R.; Viveiros, M.; Wigglesworth, K.; Eppig, J. ATRX, a member of the SNF2 family of helicase/ATPases, is required for chromosome alignment and meiotic spindle organization in metaphase II stage mouse oocytes. Dev. Biol. 2004, 272, 1-14.

73. Ostrer, H.; Huang, H.; Masch, R.; Shapiro, E. A cellular study of human testis development. Sex. Dev. 2007, 1, 286-292. 


\section{Supplementary Materials:}

Supplemental Figure S1. Co-localization of ubH2A (red, arrow) with fully synapsed chromosome bivalents (SYCP1, green) in $C b x 2^{(\mathrm{XX}-1-)}$ oocytes at the diplotene stage. Arrowhead points to faintly labeled desynapsed bivalent. Scale bar $=10 \mu \mathrm{m}$.

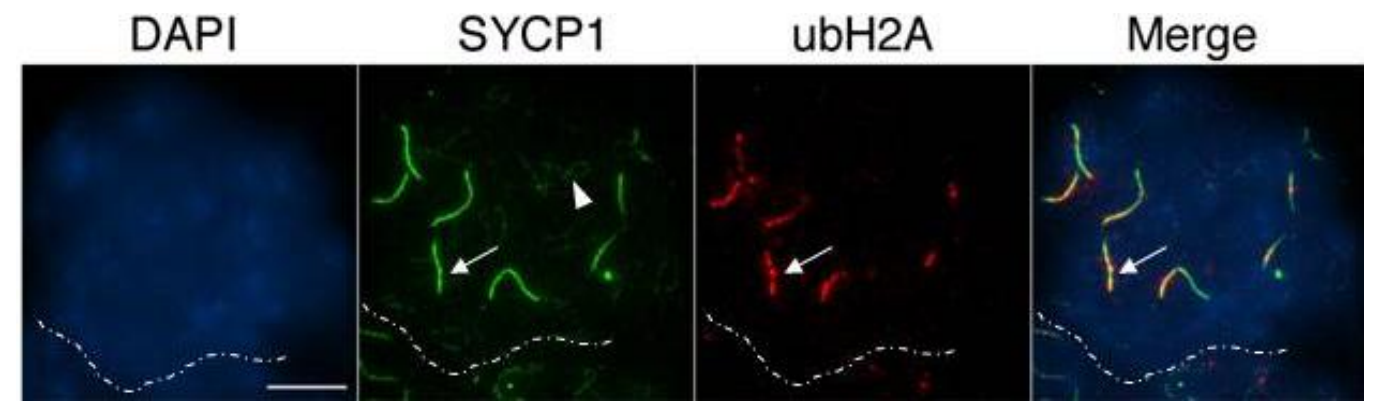

Supplemental Figure S2. Attenuation of the MSUC response (BRCA1, green) in $C b x 2^{\left(\mathrm{XX}^{-1-}\right)}$ oocytes exhibiting excessive asynapsis $(\mathrm{SYCP} 3$, red). Scale bar $=10 \mu \mathrm{m}$.

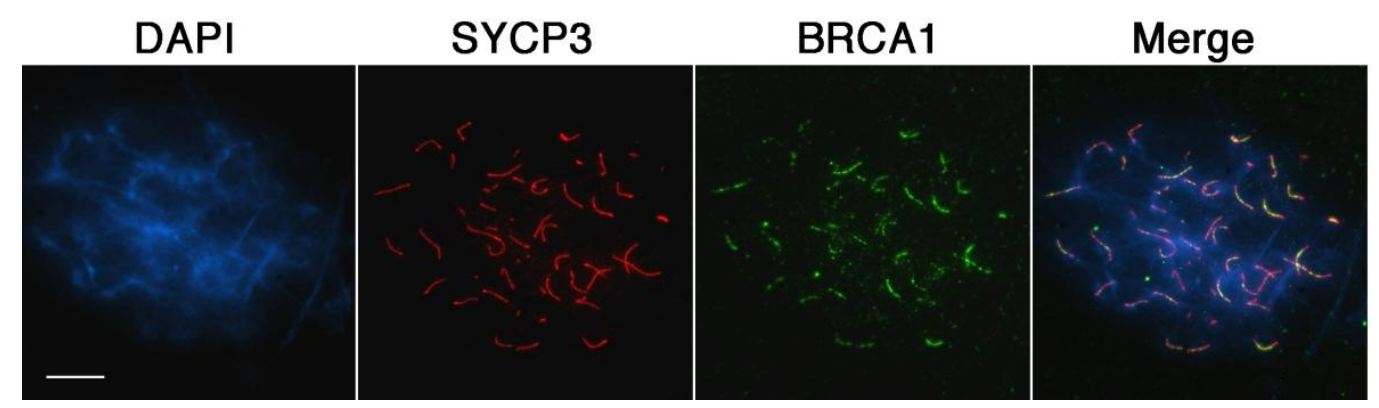

(C) 2011 by the authors; licensee MDPI, Basel, Switzerland. This article is an open access article distributed under the terms and conditions of the Creative Commons Attribution license (http://creativecommons.org/licenses/by/3.0/). 